\title{
Five years' follow-up of dental fear and anxiety, experience of dental care and oral health behaviour in Swedish preterm and full-term adolescents
}

Susanne Brogårdh-Roth ${ }^{1 *}$ (D) Johanna Månsson², Karin Ridell ${ }^{1}$, Lubna Alward ${ }^{1}$, Kristina Hellén-Halme ${ }^{3}$ and EwaCarin Ekberg ${ }^{4}$

\begin{abstract}
Background: There is rising concern about how preterm birth affects long-term health later in life. The various effects that preterm birth have on developmental outcomes, cognitive profiles and medical health may also affect levels of cooperation in the dental care situation in addition to general oral health and other oral health-related habits. Oral health is an integral part of one's general health and well-being; however, less is known about how prematurity affects oral health and other related areas such as dental care, and including dental fear and anxiety (DFA) in individuals during adolescence and adulthood. This is considered of special interest to study, as preterm children during the preschool and school period were reported to have behavioural problems during dental treatments and less than favourable oral hygiene.
\end{abstract}

Methods: A questionnaire was used of self-report design and structured into behavioural aspects relating to dental treatment, oral health-related factors, and medical health. This questionnaire at 17-19 years of age was a follow-up from 12 to 14 years of age and considered a predictor for planning future dental care for this group of patients. The 145 participating adolescents were all preterm, born between 23 and 32 weeks of gestation and 140 full-term controls, born $\geq 37$ weeks of gestation.

Results: Dental fear and anxiety, oral health behaviour, and intake of sweets and sugary drinks of 17-19-year old adolescents born preterm was comparable to that of the full-term control group. Medical health problems as well as the intake of sweets and sugary drinks increased from the time of early adolescence to late adolescence in both groups.

Conclusions: Preterm as well as full-term adolescents between 17 and 19 years of age are satisfied with their dental care and display low prevalence of dental fear and anxiety (DFA). The findings in this study indicate that adolescents born very preterm and extremely preterm are well prepared for transition to dental care in adult life with expectations of being able to take responsibility for their oral health.

Keywords: Adolescent, Born preterm, Dental care, Oral health behaviour

\footnotetext{
* Correspondence: susanne.brogardh@mah.se

'Department of Pediatric Dentistry, Faculty of Odontology, Malmö University,

SE 20506 Malmö, Sweden

Full list of author information is available at the end of the article
} 


\section{Background}

Despite recent advancements in medical care resulting in an increased survival rate, the risk remains that preterm children may develop a wide range of long-term complications in long-term health, cognitive function, and behavioural and emotional difficulties during childhood. The risk of impairment increases with decreasing gestational age, birth weight $[1,2]$ and neonatal complications [3]. Many of these have long-term consequences for health, growth, and development, with some problems continuing into adolescence and adulthood (e.g. behavioural difficulties, including long-term impairment in executive functioning and increased risk for psychiatric disorders [4-8]).

In the dental context, children and adolescents with a history of being preterm born constitute a new group of patients. Studies of behavioural problems in the dental situation expressed as uncooperative behaviour which lead to a delay in treatment, or even rendering treatment impossible, has shown that in stressful situations like dental examinations and treatments, behavior management problems (BMP) were more common in preterm children than in full-term controls during preschool and school period. Oral health problems, such as enamel defects of permanent teeth, less favourable oral hygiene, and gingival health were also more common in preterm children than full-term controls [9]. This leads to further concern about the long-term outcome of preterm children's oral health, dental care and related factors, including dental fear and anxiety (DFA). In general, knowledge about young people's views on their oral health during the transition to adulthood is limited [10]. Is prematurity a factor to highlight for dental health problems that individuals may face later in life? So far, studies have focused on children and young adolescents up to 14 years of age. To our knowledge, this study is the first to analyse oral health-related factors and dental care in older teenagers or young adults born preterm.

Adolescence is an age of transition to adulthood with expectations of being able to manage their own lives in different aspects, including taking responsibility for their general health and oral health. During this period, the adolescents evolve from being a receiver of care from parents to being a potential caregiver. A review of longterm outcomes of preterm birth concludes that preterm itself may be considered a chronic condition with risk for greater health needs in adult life [11]. Another study pointed out that a poor diet is a risk factor for cardiovascular disease, more specifically, that adults born preterm were reported to have a stronger preference for sweets than full-term born adults [12]. Such dietary habits may cause a risk for both medical and oral health problems in general. For adults born preterm, a gap of knowledge exists concerning the risk factors for poor oral health.
Given that adolescents are at an age when they are just about to leave the organized Swedish Dental Health Care system, the results from this survey may provide important information for future planning for dental care providers for this specific group of patients in transition to dental care in adult life.

The aims of the current study were to investigate experience of dental care, including DFA, satisfaction with dental care, oral health behaviour, dietary habits and medical health in preterm adolescents and full-term born controls at the age of 17-19 years in comparison with the same groups when they were between 12 and 14 years old [9].

Hypotheses:

- Due to preterm-born adolescents' greater risk of developing behavioural difficulties, they have higher levels of DFA than full-term controls at follow-up at 17-19 years of age.

- Due to a well-functioning dental care system in Sweden, preterm-born adolescents are not considered special needs patients in their future dental care because, at 17-19 years of age, they are comparable to that of the full-term control group regarding oral health behaviour, dietary habits and satisfaction with dental care.

\section{Methods \\ Study area}

This study was conducted in southern Sweden, and preterm adolescents included were born at the University Hospitals of Malmö and Lund [9].

\section{Study population}

All participants, both preterm and full-term originate from previous studies by Brogårdh-Roth 2010 [9]. In 2013 when the adolescents were 17-19 years of age, they were invited to participate in the current study. The original study sample included all adolescents born $\leq 32$ weeks in the catchment area of Malmö-Lund from 1994 to $1996(n=192)$. With access to the Swedish Medical Birth Register, information on the children's gestational age, birth weight, and number of siblings was collected from the Swedish National Board of Health and Welfare.

In the previous study, a control child born full-term was matched with every preterm child entering the study by age, sex, immigrant background (defined as at least one parent born outside the Nordic countries), dental clinic, and dental operator [13]. The same control children were invited to participate in the present survey.

In this study, the term preterm is used to describe children born at 32 weeks or earlier, very preterm to 
describe children born 29 to 32 weeks, and extremely preterm to describe children born 23 to 28 weeks.

Of the original 192 preterm adolescents, 18 declined participation for reason unknown, 21 were not reachable, and one was deceased. Further, seven preterm adolescents were unable to complete the questionnaire due to severe intellectual disabilities and were excluded. Consequently, 145 adolescents born preterm, of whom 113 very preterm and 32 extremely preterm, and 187 matched controls were included.

In the control group, 13 controls declined participation for reason unknown and 39 controls were not reachable, leaving 140 controls that agreed to participate in the present study. All the participating adolescents, except from 5 preterm and 3 controls, still lived in the same region as when aged $12-14$.

\section{Questionnaire}

The questionnaire was of a self-report design and structured into the following parts. A similar questionnaire was used at the age of 12-14 years [9].

The head items in the questionnaire (Table 1) are as follows:

- Dental fear and anxiety (Children's Fear Survey Schedule-Dental Subscale, CFSS-DS), [14]. Total scores range from 15 to 75 , children/adolescents with a score $\geq 38$ were categorized as having DFA according to Klingberg 1994 [15].

- Oral health behaviour was described in seven items $[16,17]$.

- Attitude to the dental care was described in two items: satisfaction with dental care, in general, and pain rating experienced during $\mathrm{X}$-ray. The adolescent was asked to rate the pain intensity on a $100 \mathrm{~mm}$ Visual Analogue Scale. Rating $\geq 50$ was classified as having pain in conjunction with radiographic investigations.

- Medical health included general health problems, disability, and daily medication. The following definition was used for chronic disease:

- a disorder that is disabling, chronic or incurable, or

- a disorder occurring at least three months during a one-year period and interfering with daily life functioning and/or needing treatment or special aids during at least three months, or

- a disorder requiring hospitalization for at least one month or at least three periods during a one-year period [18].

The definition of general health problems was having medical problems of lesser severity or duration, e.g., allergies or minor respiratory disorders.
- School situation consisted of questions regarding satisfaction with school situation and current education, classified as three-year theoretical or practical programs [19].

\section{Analyses and statistics}

The chi-square test was used for comparisons between the preterm and control adolescents, as well as for comparisons between sexes, between twins and singletons (within the preterm and control groups, respectively), and between the very preterm and extremely preterm groups. To assess the difference within the groups at 12-14 years and 17-19 years, Mc Nemar's test was used. Mann Whitney test was used for comparisons between the groups for all respondents regarding CFSS-DS difference. The Statistical Package for the Social Sciences (SPSS) - version 16.0, 21.0 and 23.0 - was used.

\section{Results}

The questionnaire was sent to 192 preterm adolescents and 192 controls. Of those, 145 preterm adolescents (75.5\%) and 140 controls (72.9\%) agreed to participate and returned the questionnaire.

Table 2 provides the characteristics of the study population. The mean age at the time of the questionnaire was for the preterm and control group 18.3 (range 16.819.8 years) and 18.4 (range 16.8-19.9 years) respectively.

Analysis of the dropouts shows a mean age for the preterm group of 18.1 (range 16.4-19.8), and for the controls 18.1 (range 16.4-19.8). Significantly more boys than girls among the preterm born adolescents declined participation. Among the controls there were no differences concerning sex.

\section{Questionnaire}

\section{Dental fear and anxiety (CFSS-DS score)}

There were no significant differences regarding CFSSDS scores between the adolescents in the preterm and control group at 17-19 years (Table 3). Those classified as having dental fear and anxiety (DFA - CFSS-DS score $\geq 38$ ) were $5.5 \%$ in the preterm group and $2.1 \%$ of the controls. The subgroup analyses between the sexes within the preterm and control groups revealed slightly higher CFSS-DS scores for girls than boys in both groups at both $12-14$ and 17-19 years. No other differences were revealed between very preterm and extremely preterm adolescents or between twins and singletons within the preterm group.

CFSS-DS items ranking at 17-19 years did not differ from 12 to 14 years. The items "Injection" and "Dentist drilling" were the most stressful items in both groups on both occasions. There were no statistically significant differences for any of the items between preterm and controls at either $12-14$ or $17-19$ years of age. 
Items

Dental fear and anxiety, CFSS-DS

(Children's Fear Survey

Schedule-Dental Subscale)

Oral health behaviours

- Frequency of intake of food or beverages $\geq 5$ times/day

- Frequency of eating sweets, crackers, buns, crisps/chips, between meals $\geq 3$ days/week

- Frequency of soft drinks (non-diet), tea or coffee with sugar between meals

- Frequency of toothbrushing

- Use of fluoridated toothpaste

- Use of extra fluoride supplements

- Use of dental floss

Satisfaction with dental care

- Attitude to dental care

- Pain rating concerning performed intraoral radiographs

Medical health

- Chronic illness

- General health problems

- Daily medication

School situation

- Satisfaction with school situation

- Level of education

- theoretical programmes

- practical programmes
Answers

15 items scored as follows:

$1=$ not afraid at all, $2=$ a little afraid

$3=$ quite afraid, $4=$ very afraid

$5=$ terrified

yes or no

yes or no

yes or no

$1=$ never
$2=$ once a week,
$3=2-3$ times a week,
$4=4-6$ times a week
$5=$ every day

1=very good, $2=$ good, 3=bad, 4=very bad

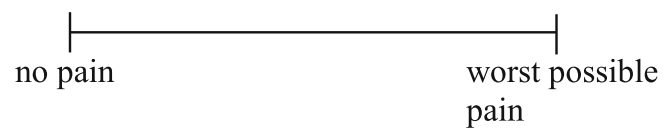

yes or no

yes or no

yes or no

1=very good, 2= good, 3=bad, 4=very bad

the name of the specific programme the name of the specific programme 
Table 2 Baseline characteristics of very preterm adolescents (VPT), extremely preterm adolescents (EPT) and full-term adolescents at 17-19 years of age

\begin{tabular}{|c|c|c|c|c|}
\hline & \multicolumn{3}{|l|}{ Preterm } & \multirow{3}{*}{$\begin{array}{l}\text { Full-term } \\
n=140\end{array}$} \\
\hline & Total & VPT & EPT & \\
\hline & $n=145$ & $n=113$ & $n=32$ & \\
\hline \multicolumn{5}{|l|}{ Sex } \\
\hline Boys & $67(46.2 \%)$ & $49(43.4 \%)$ & $18(56.3 \%)$ & $69(49.3 \%)$ \\
\hline Girls & $78(53.8 \%)$ & $64(56.6 \%)$ & $14(44.8 \%)$ & $71(50.7 \%)$ \\
\hline Twins/triplets & $47(32.4 \%)$ & $42(37.2 \%)$ & $5(15.6 \%)$ & $1(0.7 \%)$ \\
\hline \multicolumn{5}{|l|}{ Immigrant background } \\
\hline Nordic & $120(82.8 \%)$ & $98(86.7 \%)$ & $22(68.8 \%)$ & $115(82.1 \%)$ \\
\hline Immigrants & $25(17.2 \%)$ & $15(13.3 \%)$ & $10(31.3 \%)$ & 25 (17.9\%) \\
\hline Mean gestational age in weeks & 29.9 & 30.8 & 26.6 & $\geq 37$ \\
\hline (range) & $(24-32)$ & $(29-32)$ & $(24-28)$ & no data available \\
\hline Mean birth -weight (gram) & 1454 & 1604 & 922 & $3550^{\mathrm{a}}$ \\
\hline range & $615-2235$ & $840-2235$ & $615-1470$ & $2100-4400$ \\
\hline
\end{tabular}

\section{Satisfaction with dental care}

In the preterm group, 127 (87.6\%) graded their satisfaction with dental care as very good or good, compared with 117 (83.6\%) in the control group. At 12-14 years of age, the corresponding figures were $96.3 \%$ in preterm group and $97.2 \%$ in control group (Table 3 ).

\section{Oral health behaviour}

There were no statistically significant differences in oral health behaviour between preterm and controls from 12 to 14 years to 17-19 years of age. Further, subgroup analyses revealed no statistically significant differences between the sexes within the two preterm groups, or between twins and singletons within the preterm group.
Twice as many both preterm and control adolescents at 17-19 years reported snacking (sweets, crackers, etc.) between meals $\geq 3$ days/week compared with at 1214 years (preterm, $43.4 \%$ vs. $18.3 \%$; $p=0.001$ ) (controls, $49.3 \%$ vs. $24.1 \% ; p=0.009$ ) (Table 4 ). Similar figures were reported for drinking sugar containing drinks between meals (preterm, $48.9 \%$ vs. 29.4\%; $p=0.011$ ) (controls, $52.9 \%$ vs. $29.6 \% ; p=0.003$ ) (Table 4 ).

Boys, 17-19 years in both preterm and control group dominated in frequency for all dietary items. In the preterm group, there were significantly more boys than girls reported intake of food and drinks $\geq 5$ times/day (52.2\% vs. $31.6 \% ; p=0.014)$ and for drinking non-diet soda between meals $(59.7 \%$ vs. $39.7 \%$; $p=0.017)$. In the control group, significantly more boys reported

Table 3 Dental fear scores (CFSS-DS) and satisfaction with dental care in preterm (PT) and full-term adolescents (C) at 17-19 years and 12-14 years of age

\begin{tabular}{|c|c|c|c|c|c|c|}
\hline & \multicolumn{3}{|c|}{ 17-19 years of age } & \multicolumn{3}{|c|}{$12-14$ years of age } \\
\hline & PT & $C$ & $P$-value & PT & C & $P$-value \\
\hline & $n=145$ & $n=140$ & & $n=109$ & $n=108$ & \\
\hline \multicolumn{7}{|l|}{ CFSS-DS } \\
\hline mean & 21.41 & 21.58 & $0.196^{a}$ & 21.89 & 21.57 & $0.820^{\mathrm{a}}$ \\
\hline SD & 7.68 & 6.82 & & 6.37 & 5.97 & \\
\hline median & 18.00 & 20.00 & & 20.40 & 20.00 & \\
\hline range & $15-48$ & $15-61$ & & $15-47$ & $15-45$ & \\
\hline Satisfaction with the dental care & $127(87.6 \%)$ & $117(83.6 \%)$ & $0.334^{b}$ & $105(96.3 \%)$ & $105(97.2 \%)$ & $0.710^{b}$ \\
\hline Very good & $50(34.5 \%)$ & $56(40.0 \%)$ & & $51(46.8 \%)$ & $58(53.7 \%)$ & \\
\hline Good & 77 (53.1\%) & $61(44.6 \%)$ & & $54(49.5 \%)$ & $47(43.5 \%)$ & \\
\hline Bad & $18(12.4 \%)$ & $23(16.4 \%)$ & & $4(3.7 \%)$ & $3(2.8 \%)$ & \\
\hline Very bad & $0(0 \%)$ & $0(0 \%)$ & & $0(0 \%)$ & $0(0 \%)$ & \\
\hline
\end{tabular}

${ }^{\mathrm{a}}$ MannWhitney test, ${ }^{\mathrm{b}} \mathrm{Chi}$-square test 
Table 4 Frequency of daily intakes, sweets and soft drinks in preterm (PT) and full-term adolescents (C) at 17-19 years and 12-14 years of age. Chi-square test

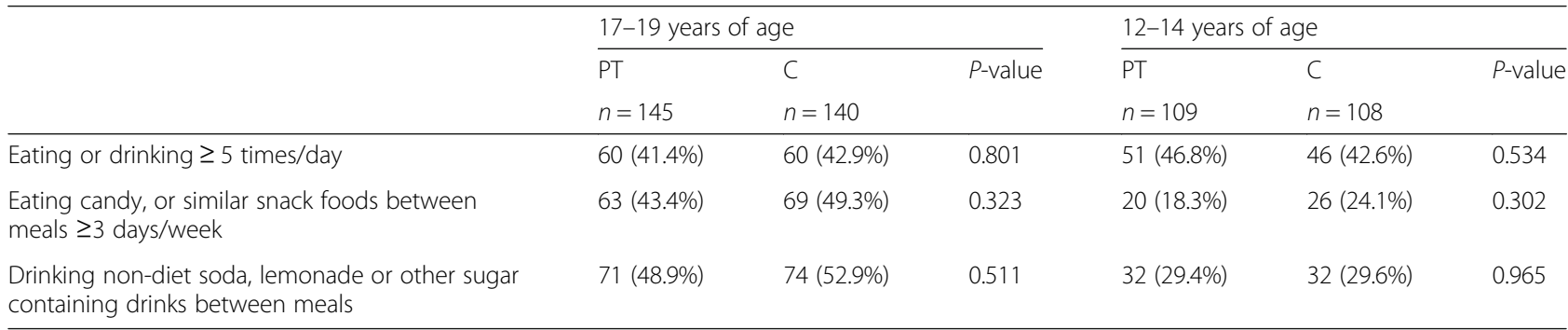

snacking between meals $\geq 3$ days/week $(66.7 \%$ vs. $32.4 \% ; p=0.000)$.

\section{Pain experienced during dental radiographs}

Regarding pain during dental radiographic investigations, 49 preterm adolescents $(33.8 \%)$ claimed experiencing pain (rating $\geq 50$ on the VAS scale) compared with 52 controls (37.1\%), a non-significant difference. Subgroup analyses revealed a significant difference between girls and boys in the preterm group $(50.0 \%$ vs. $14.9 \% ; p<0.005)$ as well as in controls $(52.1 \%$ vs. $21.7 \% ; \quad p=p<0.005)$. Extremely preterm adolescents reported pain more frequently than in very preterm group, (40.6\% vs. $31.9 \%$ ) without a significant difference.

\section{Medical health}

Chronic illness had increased from 12 to 14 years and was significantly more reported by both preterm adolescents and full-term controls at 17-19 years ( $p=0.035$ vs. $p=0.039$ ) (Table 5). A similar difference, though nonsignificant, was seen for daily medication ( $p=0.057$ vs. $p=0.581)$. Extremely preterm adolescents reported significantly more chronic illness than very preterm $(34.4 \%$ vs. $17.7 \% ; p=0.042)$. No other statistically significant differences were seen for chronic illness, general health problems, or daily medication between the sexes within the two groups, or between twins and singletons within the preterm group.

\section{School situation}

The majority of preterm and control adolescents reported satisfaction with their school situation at both $17-19$ years (93.8\% vs. $96.4 \%)$ and $12-14$ years $(97.2 \%$ vs 98.1\%). With the former, $95.9 \%$ of the preterm group and $97.9 \%$ of the full-term control attended national programs at ordinary high school programs. Fewer in the preterm group followed a theoretical programme (67.6\%) compared with full-term controls (75.8\%); however, this is a non-significant difference.

\section{Discussion \\ Main findings}

In this survey, the majority of both preterm and controls rated their experience of dental care as very good or good, which is a sustaining result for the dental care system and may reflect a low overall rate of dental fear and anxiety (DFA). It appears that the transition from pediatric dentistry to adult dental care for all adolescents are well prepared. Results concerning DFA, oral health behaviour, and intake of sweets and sugary containing drinks of 17-19-year-old adolescents born preterm was comparable to that of the full-term control group. Thus, the proposed hypothesis that preterm adolescents would have higher levels of CFSS-DS scores than full-term control group is rejected. The expectation was that it would be higher in the preterm group because of the correlation to the reported increased risk for anxiety/ depression during adolescence and young [6]. According to a meta-analysis, those born preterm or low birth weight were three times more likely to receive a diagnosis of a psychiatric condition, including anxiety and depression, in late childhood, adolescence and young adulthood [6]. Furthermore, different aspects of anxiety and depressive symptoms have been reported to be risk factors during early adulthood for dental fear and anxiety [20].

DFA refers to the patient's experiences in dental care and is related to characteristics like temperamental factors and psychiatric problems as reported in preterm children $[21,22]$, and therefore, relevant to study. The prevalence of DFA is approximately $9 \%$ in a child population [23] and around $20 \%$ in an adult population [24]. In relation to this survey, the results showed $5.5 \%$ in the preterm group and $2.1 \%$ of the controls. In several population studies, CFSS-DS is the most frequently used measure of DFA, and the mean scores are lower than previously reported rates in adolescents [23] but fall in line with data from a study of 13-19-year-old Swedish adolescents, comparable as a reference group [25]. Also, the finding that girls had higher levels of CFSS-DS scores in both preterm and control groups is in line with previous population studies [23]. 
Table 5 Medical health in preterm (PT) and full-term adolescents (C) at 17-19 years and 12-14 years of age. Chi-square test

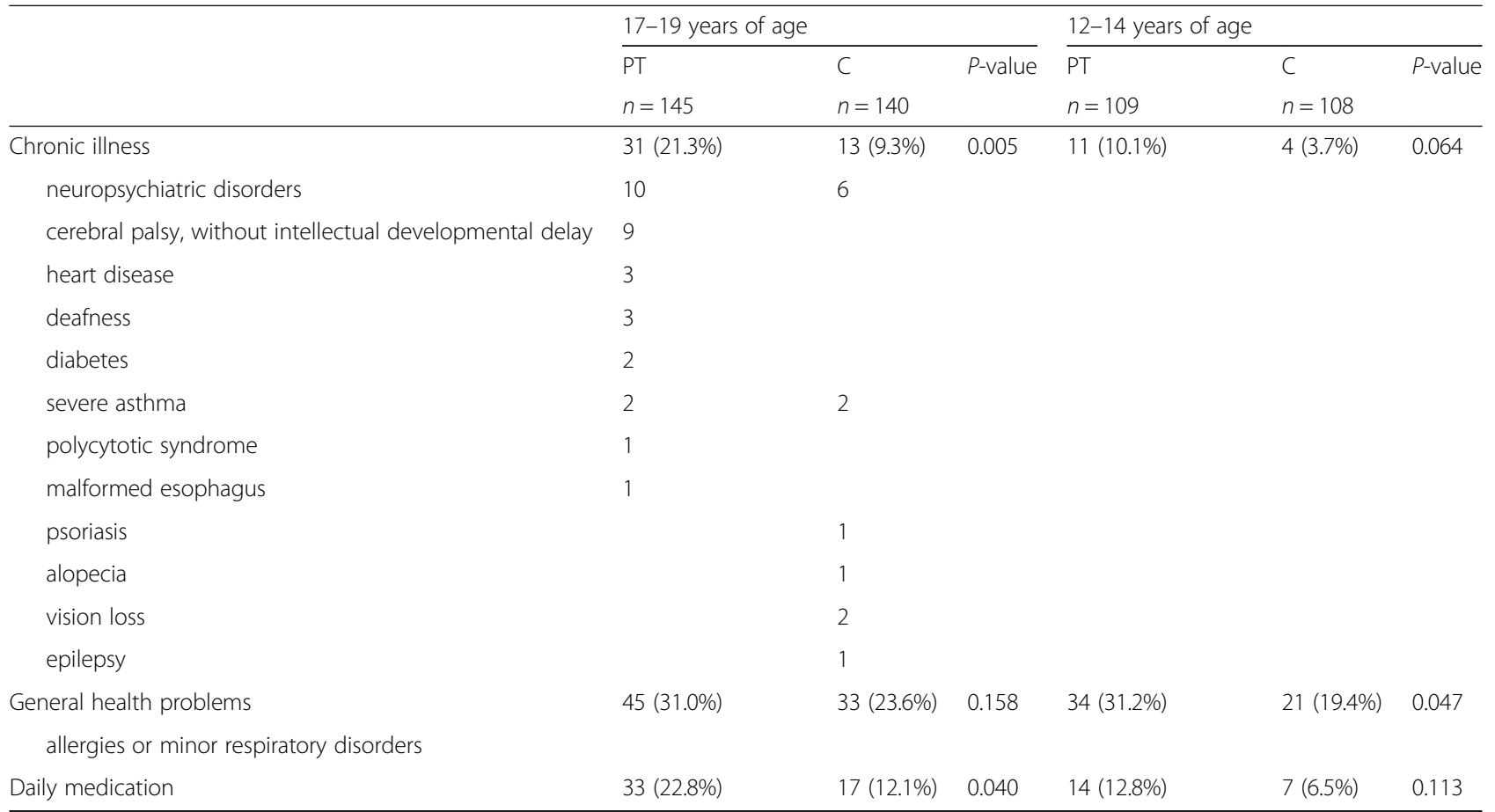

The hypotheses that adolescents born preterm are not to be considered as special needs patients in future dental care is partly rejected. Almost $50 \%$ of the adolescents reported consuming sweets and sugary drinks between meals several days per week, although in comparisons with full-term controls. The frequent consumption of soft drinks may increase the risk of caries and dental erosion [26], and it is linked to an unhealthy lifestyle in general. That more boys than girls reported a frequent intake of sweets and soft drinks several times per week is in line with a recent Swedish study of 16 year olds which named the consumption of sweets and soft drinks as a risk factor for being overweight and obese later in life, and therefore, a public health concern also from this perspective [27]. In comparison with early adolescence, the reported consumption of sweets and sugary drinks between meals several days per week in this survey had increased by about $100 \%$ in both groups. For the preterm group, with their increasingly compromized health status during adolescence, this reflects that pretermborn adolescents may be potentially at risk for oral health problems in adult life. Further, according to Sharafi et al. 2016 [12], less healthy dietary behaviours contribute to risk factors for cardiovascular disease in young adults born preterm.

The adolescent's health status in this study increased twice from early adolescence (12-14 years) to late adolescence (17-19 years) in both the preterm and control group. These health problems included, for example, neuropsychiatric disorders, asthma, chronic lung disease, diabetes, and hearing impairments, with a prevalence of $34.4 \%$ in extremely preterm $17-19$ year olds. These figures are in comparison with another Swedish study with extremely preterm 18-year-old adolescents reporting $37.6 \%$ chronic illness [28].

Dental procedures can be associated with pain, unpleasant feelings, and worry, and may result in stress and anxiety [29]. How the pain is perceived and rated relates to, for example, age, gender, and previous dental experiences [30]. Highly anxious children reported more pain than less anxious children [31]. Further, research suggests that preterm children's experience of pain during neonatal intensive care might influence later pain sensitivity [32] and might contribute to adverse longterm physiologic and behavioural sequelae [33]. A radiographic examination is a common part of clinical dental examination and might be associated with more or less pain for everyone, even adults. The results from this survey showed that girls in both preterm and the control group rated significantly more pain than boys during radiographic exposure. This corresponds well with previous results reported by Krekmanova et al. 2009 [30]. To our knowledge, few studies have been carried out on pain sensitivity in the dental situation in preterm children. The finding that $41 \%$ of extremely adolescents and $32 \%$ of very preterm adolescents claimed pain associated with this examination suggests further exploration. The combination of common reported illness of 
differing severity and lower cognitive function, as frequently reported in preterm children, increases the importance of identifying pain management strategies [33], this may also include dental procedures.

\section{Study limitations}

A limitation of the study is the small number of extremely preterm participants, making comparisons within the preterm group difficult; however, this falls in line with official statistics in Sweden. Further, the longitudinal study design made it impossible to include a larger number of extremely preterm individuals.

\section{Study strengths}

This study was population-based and is a follow-up of a group surveyed from 3 to 14-years of age [9]. Consequently, the response rate of $76 \%$ in preterm and $73 \%$ in the control group is considered a satisfactory return. Another strength was the use of the same measurements and method of compiling data as in the previous study at 12-14 years. Further, the same examiner (SBR) carried out the studies on both occasions.

\section{Conclusions}

The majority of the adolescents were satisfied with their dental care, and it seems like the transition from pediatric dentistry to adult dental care for all adolescents are well prepared. Although CFSS-DS, oral health behaviour, and intake of sweets and sugary drinks of 17-to-19year old adolescents born preterm was comparable to that of the full-term control group, the number of chronic diseases and daily medication increased significantly in the preterm group. The combination of unhealthy dietary habits and chronic illness, as reported for preterm adolescents, needs to be further explored in preterm-born adults and may also be of interest from a medical point of view.

\section{Abbreviations}

BMP: Behaviour management problems; CFSS-DS: Children's fear survey schedule-dental subscale; DFA: Dental fear and anxiety; EPT: Extremely preterm born (gestational weeks 23-28); PT: Preterm born (gestational weeks 23-32); VPT: Very preterm born (gestational weeks 29-32)

\section{Acknowledgements}

The authors express their appreciation to all participants of this study for taking their time to fill in the questionnaires. This study was approved by the Faculty of Odontology, Malmö University.

\section{Funding}

This study was supported by grants from the Faculty of Odontology, Malmö University.

\section{Availability of data and materials}

The datasets used and/or analysed during the current study are available from the corresponding author on reasonable request.

\section{Authors' contributions}

All authors have contributed to this study in different ways. SBR designed the data collection, carried out the analyses and was responsible for the manuscript and all revisions. JM and KR critically reviewed the manuscript. $\mathrm{KHH}$ contributed to the study design and reviewed the manuscript. LA contributed to the data collection and reviewed the manuscript. ECE contributed to the study design and critically reviewed the analyses and the manuscript. All authors have approved the final version.

\section{Authors' information}

The present study is a part of a national comprehensive project that also includes oral health related quality of life (OHIP), TMD pain (Temporo Mandibular Disorder) and patients' views of orthodontic treatment. Further, it is an ongoing collaboration with the Department of Psychology at Lund University regarding adolescents' experiences of emotional health, social support and close relationships. To study the oral health, including the overall treatment received by both groups is also an ongoing research project at Malmö University. The purpose from a dental point of view is to study preterm children and adolescents from a lifespan perspective.

Ethics approval and consent to participate

The Ethics Committee of the Medical Faculty of Lund University approved previous studies, from which the material was collected (Dnr LU 362-01, Dnr 618/2007), and the present questionnaire study (Dnr Etik H15 2013/39). The adolescents and parents were posted written information about the study, including confidential and voluntary participation with the right to discontinue participation at any time. A written informed consent form was attached along with the questionnaires to request the parent's and the adolescents consent. The questionnaire with a reminder was sent out twice; a further reminder was conducted by telephone.

Consent for publication

Not applicable.

Competing interests

The authors declare that they have no competing interests.

\section{Publisher's Note}

Springer Nature remains neutral with regard to jurisdictional claims in published maps and institutional affiliations.

\section{Author details}

'Department of Pediatric Dentistry, Faculty of Odontology, Malmö University, SE 20506 Malmö, Sweden. ${ }^{2}$ Department of Psychology, Lund University, Lund, Sweden. ${ }^{3}$ Department of Oral and Maxillofacial Radiology, Faculty of Odontology, Malmö University, Malmö, Sweden. ${ }^{4}$ Department of Stomatognathic Physiology, Faculty of Odontology, Malmö University, Malmö, Sweden.

Received: 12 June 2017 Accepted: 19 November 2017

Published online: 04 December 2017

References

1. Hack M, Fanaroff AA. Outcomes of children of extremely low birthweight and gestational age in the 1990s. Semin Neonatal. 2000;5:89-106. Review

2. Johnson S, Fawke J, Hennessy E, Rowell V, Thomas S, Wolke D, Marlow N. Neurodevelopmental disability through 11 years of age in children born before 26 weeks of gestation. Pediatrics. 2009;124:e249-57.

3. Lundequist A, Böhm B, Lagercrantz $H$, Forssberg H, Smedler AC. Cognitive outcome varies in adolescents born preterm, depending on gestational age, intrauterine growth and neonatal complications. Acta Paediatr. 2015;104:292-9.

4. Saigal S, Doyle LW. An overview of mortality and sequelae of preterm birth from infancy to adulthood. Lancet. 2008;371:261-9.

5. Allin M, Walshe M, Fern A, Nosarti C, Cuddy M, Rifkin L, Murray R, Rushe T, Wyatt J. Cognitive maturation in preterm and term born adolescents. J Neurol Neurosurg Psychiatry. 2008;79:381-6.

6. Burnett AC, Anderson PJ, Cheong J, Doyle LW, Davey CG, Wood SJ. Prevalence of psychiatric diagnoses in preterm and full-term children, adolescents and young adults: a meta-analysis. Psychol Med. 2011;41:2463-74. 
7. Elgen IB, Holsten F, Odberg MD. Psychiatric disorders in low birthweight young adults. Prevalence and association with assessments at 11 years. Eur Psychiatry. 2013;28:393-6.

8. Linsell L, Malouf R, Johnson S, Morris J, Kurinczuk JJ, Marlow N. Prognostic factors for behavioral problems and psychiatric disorders in children born very preterm or very low birth weight: a systematic review. J Dev Behav Pediatr. 2016:37:88-102.

9. Brogårdh-Roth S. The preterm child in dentistry. Behavioural aspects and oral health. Swed dent J. Suppl 2010;(208):11-85. Thesis.

10. Johansson G, Östberg AL. Oral health-related quality of life in Swedish young adults. Int J Qual Stud Health Well-being. 2015;10:27125. doi:10.3402/qhw.v10.27125.

11. Raju TNK, Buist S, Blaisdell CJ, Moxey-Mims M, Saigal S. Adults born preterm: a review of general health and system-specific outcomes. Acta Paediatr. 2017;106:1409-37. doi:10.1111/apa.13880.

12. Sharafi M, Duffy VB, Miller RJ, Winchester SB, Huedo-Medina TB, Sullivan MC. Dietary behaviors of adults born prematurely may explain future risk for cardiovascular disease. Appetite. 2016;99:157-67. doi:10.1016/j.appet.2016.01.007

13. Brogårdh-Roth S, Stjernqvist K, Matsson L. Dental behavioural management problems and dental caries prevalence in 3- to 6-year-old Swedish children born preterm. Int J Paediatr Dent. 2008;18:341-7.

14. Cuthbert MI, Melamed BGA. Screening device: children at risk for dental fears and management problems. ASDC J Dent Child. 1982:48:432-6.

15. Klingberg G. Reliability and validity of the Swedish version of the dental subscale of the Children's fear survey schedule, CFSS-DS. Acta Odontol Scand. 1994;52:255-6.

16. Arnrup K, Berggren U, Broberg AG. Usefulness of a psychometric questionnaire in exploring parental attitudes in children's dental care. Acta Odontol Scand. 2001;59:14-20.

17. Blomqvist M, Holmberg K, Fernell E, Ek U, Dahllöf G. Dental caries and oral health behavior in children with attention deficit hyperactivity disorder. Eur J Oral Sci. 2007;115:186-91.

18. Westbom L, Kornfält R. Chronic illness among children in a total population. An epidemiological study in a Swedish primary health care district. Scand J Soc Med. 1987;15:87-97.

19. Upper Secondary School 2011. In Swedish: Skolverket, 2011 http:// wwwskolverketse/publikationer?id=2801. Accessed October 2016.

20. Halonen H, Salo T, Hakko H, Räsänen P. Association of dental anxiety to personality traits in a general population sample of Finnish university students. Acta Odontol Scand. 2012;70:96-100.

21. Johnson S, Marlow N. Preterm birth and childhood psychiatric disorders. Pediatr Res. 2011;69:11R-8R.

22. Stjernqvist K, Svenningsen NW. Ten-year follow-up of children born before 29 gestational weeks: health, cognitive development, behaviour and school achievement. Acta Paediatr. 1999;88:557-62.

23. Klingberg G, Broberg A. Dental fear/anxiety and dental behaviour management problems in children and adolescents - a review of prevalence and concomitant psychological factors. Int J Paediatr Dent. 2007;17:391-06.

24. Wide Boman U, Carlsson V, Westin M, Hakeberg M. Psychological treatment of dental anxiety among adults: a systematic review. Eur J Oral Sci. 2013;121:225-34.

25. Gustafsson A, Arnrup K, Broberg AG, Bodin L, Berggren U. Child dental fear as measured with the dental subscale of the Children's fear survey schedule: the impact of referral status and type of informant (child versus parent). Community dent oral. Epidemiology. 2010;38:256-66.

26. Hasselkvist A, Johansson A, Johansson AK. Association between soft drink consumption, oral health and some lifestyle factors in Swedish adolescents. Acta Odontol Scand. 2014;72:1039-46.

27. Winkvist A, Hultén B, Kim JL, Johansson I, Torén K, Brisman J, Bertéus Forslund $\mathrm{H}$. Dietary intake, leisure time activities and obesity among adolescents in western Sweden: a cross-sectional study. Nutr J. 2016;21:15-41.

28. Hallin AL, Hellström-Westas L, Stjernqvist K. Follow-up of adolescents born extremely preterm: cognitive function and health at 18 years of age. Acta Paediatr. 2010;99:1401-6.
29. Klaassen MA, Veerkamp JS, Hoogstraten J. Dental fear, communication, and behavioural management problems in children referred for dental problems. Int J Paediatr Dent. 2007;17:469-77.

30. Krekmanova L, Bergius M, Robertson A, Sabel N, Hafström C, Klingberg G, Berggren U. Everyday- and dental-pain experiences in healthy Swedish 8-19 year olds: an epidemiological study. Int J Paediatr Dent. 2009;19:438-47.

31. Versloot J, Veerkamp JS, Hoogstraten J. Computerized anesthesia delivery system vs. traditional syringe: comparing pain and pain-related behavior in children. Eur J Oral Sci. 2005;113:488-93.

32. Vinall J, Grunau RE. Impact of repeated procedural pain-related stress in infants born very preterm. Pediatr Res. 2014;75:584-7.

33. Hatfield LA. Neonatal pain: What's age got to do with it? Surg Neurol Int. 2014;5:S479-89.

\section{Submit your next manuscript to BioMed Central and we will help you at every step:}

- We accept pre-submission inquiries

- Our selector tool helps you to find the most relevant journal

- We provide round the clock customer support

- Convenient online submission

- Thorough peer review

- Inclusion in PubMed and all major indexing services

- Maximum visibility for your research

Submit your manuscript at www.biomedcentral.com/submit
) Biomed Central 